\title{
Combustor Operability and Performance Verification for HIFiRE Flight 2
}

\author{
Andrea M. Storch* and Michael Bynum ${ }^{\dagger}$ \\ ATK Space Systems Group, NASA Langley Research Center, Hampton, Virginia 23861 \\ Jiwen Liu \\ Taitech, Inc., Wright-Patterson AFB, Ohio 45433 \\ Mark Gruber $§$ \\ Air Force Research Laboratory, Wright-Patterson AFB, Ohio 45433
}

\begin{abstract}
As part of the Hypersonic International Flight Research Experimentation (HIFiRE) Direct-Connect Rig (HDCR) test and analysis activity, three-dimensional computational fluid dynamics (CFD) simulations were performed using two Reynolds-Averaged Navier Stokes solvers. Measurements obtained from ground testing in the NASA Langley ArcHeated Scramjet Test Facility (AHSTF) were used to specify inflow conditions for the simulations and combustor data from four representative tests were used as benchmarks. Test cases at simulated flight enthalpies of Mach 5.84, 6.5, 7.5, and 8.0 were analyzed. Modeling parameters (e.g., turbulent Schmidt number and compressibility treatment) were tuned such that the CFD results closely matched the experimental results. The tuned modeling parameters were used to establish a standard practice in HIFiRE combustor analysis. Combustor performance and operating mode were examined and were found to meet or exceed the objectives of the HIFiRE Flight 2 experiment. In addition, the calibrated CFD tools were then applied to make predictions of combustor operation and performance for the flight configuration and to aid in understanding the impacts of ground and flight uncertainties on combustor operation.
\end{abstract}

\section{Nomenclature}

$\begin{array}{ll}A & =\text { cross-sectional area } \\ C C & =\text { compressibility correction } \\ E & =\text { total energy flow rate } \\ h & =\text { enthalpy } \\ k & =\text { turbulent kinetic energy } \\ K E & =\text { kinetic energy flow rate } \\ m_{0} m_{i} & =\text { momentum components } \\ M_{\infty} & =\text { flight Mach number } \\ n & =\text { unit vector } \\ P & =\text { pressure } \\ P r_{t} & =\text { turbulent Prandtl number } \\ q_{\infty} & =\text { flight dynamic pressure } \\ S c_{t} & =\text { turbulent Schmidt number } \\ T & =\text { temperature } \\ U & =\text { velocity component }\end{array}$

\footnotetext{
* Aerospace Engineer, ATK/Hypersonic Airbreathing Propulsion Branch. Senior Member.

$\dagger$ Aerospace Engineer, ATK/Hypersonic Airbreathing Propulsion Branch.

$\$$ Senior Research Scientist. Associate Fellow.

$\S$ Principal Aerospace Engineer, AFRL/RZAS. Associate Fellow.
}

American Institute of Aeronautics and Astronautics 


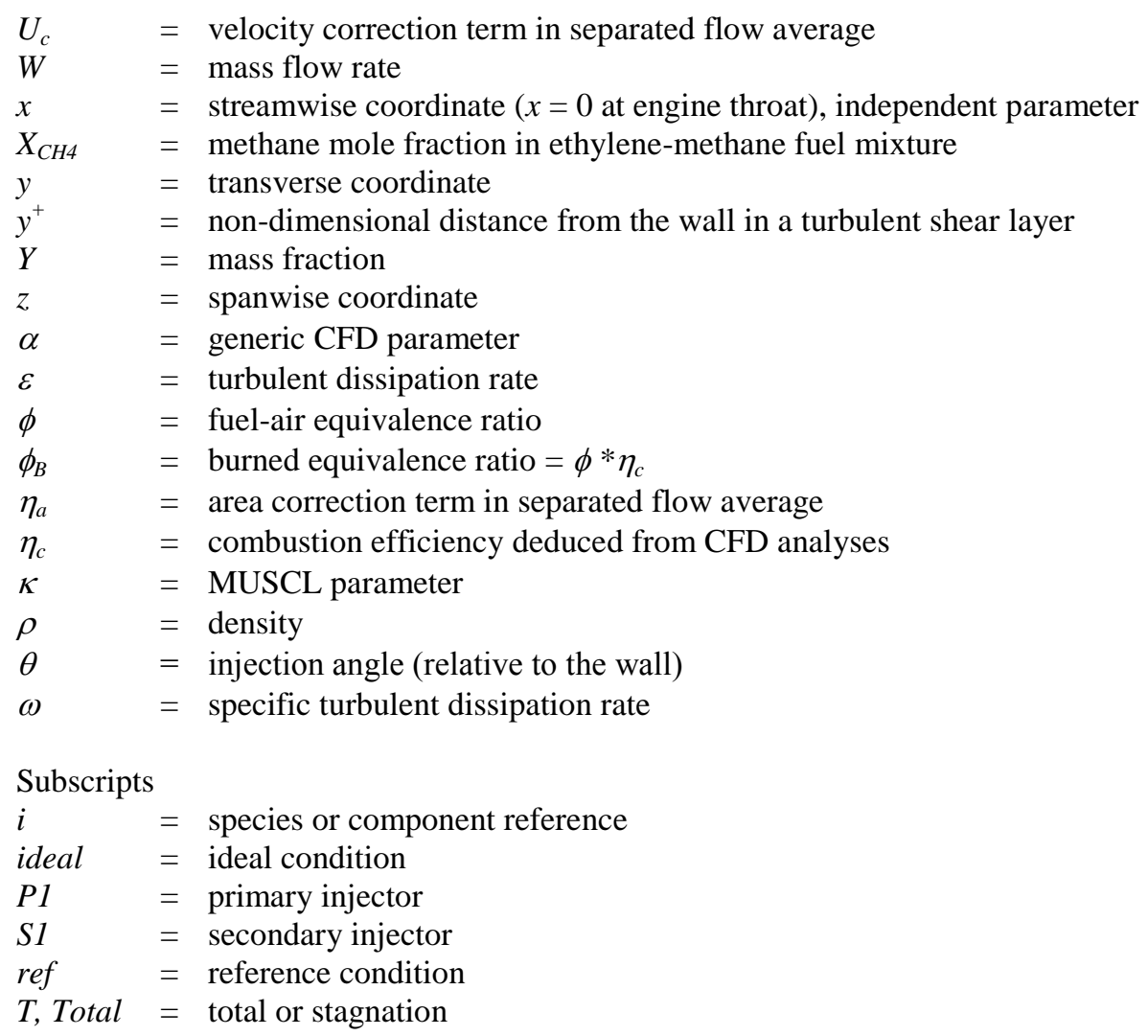

\title{
I. Introduction
}

\begin{abstract}
A collaborative international research effort, the Hypersonic International Flight Research Experimentation (HIFiRE) Program aims to study basic hypersonic phenomena through flight experimentation. A number of test flights are planned, with some designated to study the operation, performance, and stability characteristics of hydrocarbon-fueled supersonic combustors. Within this program, the HIFiRE Flight 2 (HF2) project team is led by the US Air Force Research Laboratory (AFRL) with the Australian Defence Science and Technology Organisation (DSTO) and NASA as vested partners. HF2 will utilize an alternative test technique, following a rocket-boosted suppressed trajectory, for acquiring high enthalpy supersonic combustion flight test data, and will explore Mach 8, hydrocarbon-fueled combustor performance and dual-to-scram mode transition in flight. Additionally, HF2 will incorporate in-stream laser-based instrumentation at the combustor exit plane. This instrumentation will use diode laser absorption spectroscopy to measure water concentration, temperature, and pressure in the combustor exhaust. A complete list of primary and secondary objectives for the flight experiment is presented in Table $1 .{ }^{1}$

The HIFiRE program follows the HyShot ${ }^{2}$ and HYCAUSE ${ }^{3}$ programs and aims to leverage much of the lowcost flight test technique developed in those programs. HF2 will be a first of its kind contribution to accelerating supersonic combustion research. It will utilize suppressed trajectories using a sounding rocket propelled test article to enable studies of dual-to-scram mode transition and supersonic combustion performance. To date, the combination of CFD and ground tests has been used to develop the isolator/combustor flowpath for this flight experiment. ${ }^{4}$ In the current work, ground test results from a full-scale direct-connect flowpath are used in conjunction with CFD analyses to calibrate the numerical modeling parameters so that the CFD tools can be applied under similar conditions with improved confidence. This paper will summarize the ground test approach and benchmark ground test results identified for CFD validation. It will also describe the analysis tools, the approach used in the simulations, the specific analysis results, and comparisons of those results with the ground test data.
\end{abstract}




\section{Ground Test Summary}

Figure 1 shows the isolator/combustor flowpath design that will be used in HF2 (flow direction is from left to right). This flowpath features a constant area isolator section, flush-wall fuel injection from primary (P1) and secondary (S1) injector sites, opposed cavity-based flameholders with spark plugs and injectors (CI) for ignition, and a constant divergence angle through the combustor (total included angle $=2.6^{\circ}$ ). The cross-sectional dimensions at the isolator entrance are 1-inch $\mathrm{x} 4$-inches and the overall length is just over 28 inches. The width remains constant throughout the rectangular flowpath. ${ }^{4}$

Table 1. Research objectives for HIFiRE Flight 2.

\begin{tabular}{l|l}
\hline \hline \multicolumn{1}{c}{ Primary Objectives } \\
\hline ID & \multicolumn{1}{c}{ Description } \\
\hline P1 & Evaluate scramjet engine performance and operability through a dual-to-scram mode transition \\
\hline P2 & Achieve combustion performance of $\phi_{B} \geq 0.7$ at Mach 8 flight conditions using a hydrocarbon fuel \\
\hline P3 & $\begin{array}{l}\text { Demonstrate a scramjet flight test approach that provides a variable Mach number flight corridor at } \\
\text { nearly constant dynamic pressure }\end{array}$ \\
\hline & \multicolumn{1}{c}{ Secondary Objectives } \\
\hline ID & \multicolumn{1}{c}{ Description } \\
\hline S1 & Provide a test bed for diode laser-based instrumentation \\
\hline S2 & $\begin{array}{l}\text { Acquire high-fidelity core-flow measurements of combustion products (water) in a scramjet } \\
\text { operating environment up through Mach } 8 \text { flight conditions }\end{array}$ \\
\hline S3 & Evaluate the lean blow-out characteristics of a hydrocarbon fueled scramjet at or above Mach 8 \\
\hline S4 & Evaluate a gaseous fuel mixture as a surrogate for a cracked liquid hydrocarbon fuel \\
\hline S5 & Validate existing design tools for scramjet inlet, isolator, combustor, and nozzle components \\
\hline \hline
\end{tabular}

A full-scale direct-connect version of the flowpath shown in Figure 1 has been thoroughly characterized in NASA's Arc-Heated Scramjet Test Facility (AHSTF). ${ }^{5}$ This test facility is commonly operated in free jet mode, but it has been modified to support direct-connect testing of this hydrocarbon-fueled flowpath. Test conditions covering the range of interest to the HF2 experiment $\left(M_{\infty}=6-8\right)$ are achievable in AHSTF using three facility nozzles (nozzle exit Mach 2.51, 3.00, and 3.46). For this phase of HDCR testing, the Mach 3.0 nozzle was not used. The flowpath is a modular design using thermal barrier coated copper for the walls. It is heavily instrumented with 144 pressure taps, 19 thermocouples, and four heat flux gauges. Various fuel injection configurations are available with this hardware. The baseline injection configuration, as shown in Table 2, was employed for all results shown in this paper. Cavity injectors were used for ignition only at Mach 8 enthalpy test conditions. For all cases considered in this paper, the combustor fuel was a binary mixture of ethylene and methane, where the methane mole fraction was $X_{C H 4}=0.36{ }^{6}{ }^{6}$ The fuel total temperature for all cases was $540^{\circ} \mathrm{R}$.

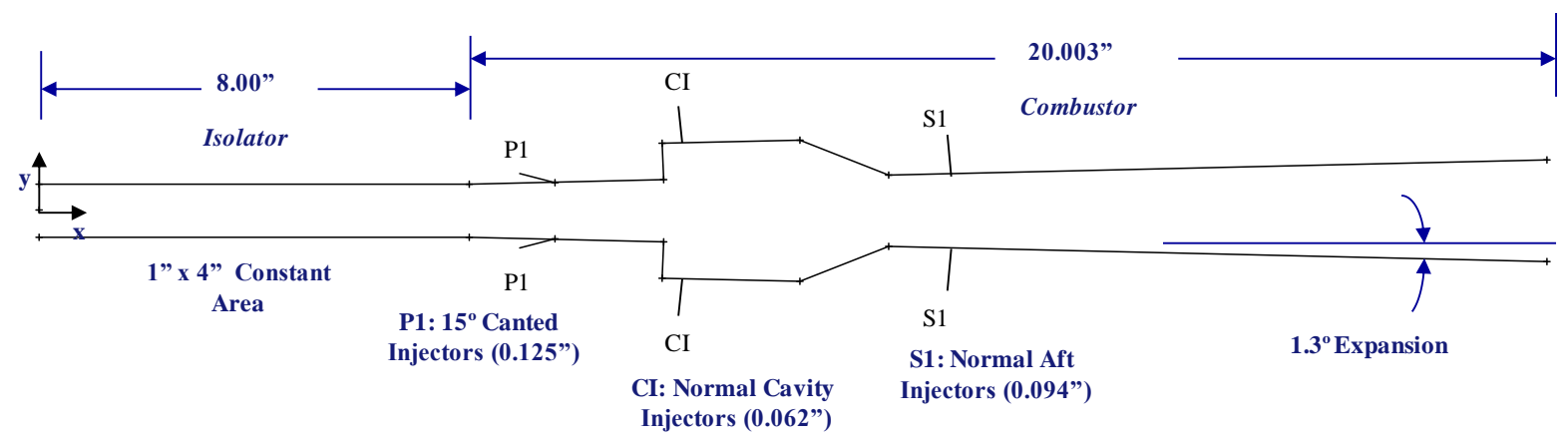

Figure 1. Side view of isolator/combustor flowpath schematic. 
Table 3 shows the specific test cases identified for detailed analysis. ${ }^{7,8}$ The inflow boundary condition for each case consisted of the conditions shown in the facility plenum. The facility nozzle was also modeled in each case. A one-dimensional heat transfer wall boundary condition was applied in the nozzle, using one backside wall temperature for the sidewall and one for the body and cowl sides.

Table 2. Baseline fuel injection configuration.

\begin{tabular}{c|c|c|c|c}
\hline \hline \multirow{2}{*}{ Injector Station } & \multicolumn{2}{|c|}{$\begin{array}{c}\text { Number of } \\
\text { Injectors }\end{array}$} & \multirow{2}{*}{ Diameter (inch) } & \multirow{\theta}{*}{ (degrees) } \\
\cline { 2 - 3 } & Body & Cowl & & \\
\hline P1 & 4 & 4 & 0.125 & 15 \\
\hline S1 & 4 & 4 & 0.094 & 90 \\
\hline
\end{tabular}

Table 3. Selected test cases for detailed analysis.

\begin{tabular}{|c|c|c|c|c|c|c|c|}
\hline \multirow[b]{2}{*}{$\begin{array}{c}\text { Test Reference } \\
\text { (Run \#; time slice) }\end{array}$} & \multirow{2}{*}{$\begin{array}{c}\text { Simulated } \\
\text { Flight Mach } \\
\text { Number }\end{array}$} & \multirow[b]{2}{*}{$\begin{array}{l}\text { Facility Nozzle } \\
\text { Mach Number }\end{array}$} & \multicolumn{2}{|c|}{ Plenum Conditions } & \multirow[b]{2}{*}{$\phi_{\text {Total }}$} & \multirow[b]{2}{*}{$\phi_{\mathrm{P} 1}$} & \multirow[b]{2}{*}{$\phi_{\mathrm{S} 1}$} \\
\hline & & & $\begin{array}{c}\mathbf{T}_{\mathrm{T}} \\
\left({ }^{0} \mathbf{R}\right)\end{array}$ & $\begin{array}{c}\mathbf{P}_{\mathrm{T}} \\
\text { (psia) }\end{array}$ & & & \\
\hline $123.1 ; 7.5 \mathrm{sec}$. & 5.84 & 2.51 & 2790 & 215 & 0.65 & 0.15 & 0.50 \\
\hline $125.1 ; 12.0 \mathrm{sec}$. & 6.5 & 2.51 & 3326 & 217 & 1.00 & 0.40 & 0.60 \\
\hline $135.6 ; 19.0 \mathrm{sec}$. & 7.5 & 3.46 & 4297 & 634 & 1.00 & 0.30 & 0.70 \\
\hline $136.3 ; 18.0 \mathrm{sec}$. & 8.0 & 3.46 & 4625 & 620 & 1.00 & 0.40 & 0.60 \\
\hline
\end{tabular}

Measured pressure distributions from the four cases identified in Table 3 are shown in Figure 2. In each plot, pressure data are shown for both tare (fuel off) and fueled conditions. These plots include pressure measurements from all four walls of the flowpath. The isolator/combustor flowpath is also shown on each plot for reference. In each case, the combustion-induced pressure rise is clearly evident. For the Mach 5.84 and 6.5 conditions, the precombustion shock train is positioned upstream of the primary injectors in the isolator. At the higher Mach number conditions, pressure rise begins very near the primary fuel injectors.

\section{Computational Resources}

Three-dimensional CFD simulations were performed using the VULCAN and CFD++ codes. VULCAN ${ }^{9}$ is a structured, three-dimensional, cell-centered, multi-bock grid, finite volume flow solver for reacting and non-reacting fluids ranging from subsonic to hypersonic speeds. The fluid can be solved as a calorically perfect gas or as a mixture of thermally perfect gases. Steady state solutions can be obtained using a diagonalized approximate factorization (DAF) scheme or an incomplete lower/upper (ILU) factorization scheme. Wall matching functions and multi-grid methods for elliptic and space marching schemes are available to reduce computational cost. Flow solver capabilities include models for compressibility, Reynolds stress anisotropies, turbulent diffusivity, finite rate chemistry, and turbulence-chemistry interaction effects. Available turbulence models include several one and twoequation models as well as large eddy simulation (LES) and hybrid Reynolds-Averaged Navier-Stokes (RANS) / LES options.

For the current work, steady state, thermally perfect solutions were obtained using the DAF scheme with the wall matching functions of Wilcox. ${ }^{10}$ The turbulence model used was the blended 1988 Wilcox $k-\omega$ and the Jones Launder $k-\varepsilon$ model of Menter. ${ }^{11}$ The inviscid fluxes were solved using the low-diffusion flux split scheme of Edwards. ${ }^{12}$ To ensure that the solution would be total variation diminishing (TVD), the van Leer flux limiter was used. The monotone upstream-centered scheme for conservation laws (MUSCL) interpolation coefficient, $\kappa$, was chosen to be 1/3. The turbulent Prandtl number $\left(\operatorname{Pr}_{t}\right)$, which determines the turbulent transport of energy was set to be 0.89 for all of the cases. The turbulent Schmidt number $\left(S c_{t}\right)$, which determines the turbulent transport of mass, and the compressibility correction were varied to calibrate the model for all cases. The turbulence-chemistry interaction model used was the eddy dissipation concept (EDC) of Magnussen and Hjertager. ${ }^{13}$ This model allowed for significantly reduced computational requirements and is valid for mixing-limited solutions such as those in the current work. 


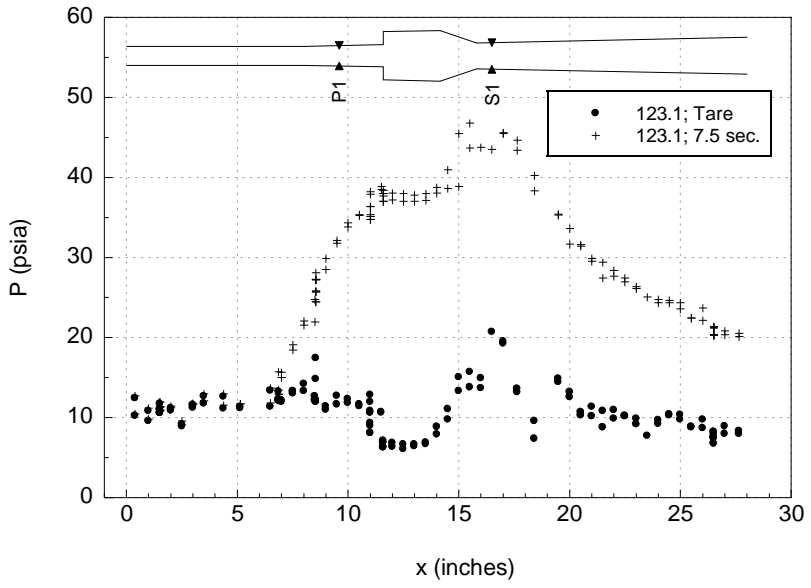

(a) Run 123.1, $M_{\infty}=5.84$

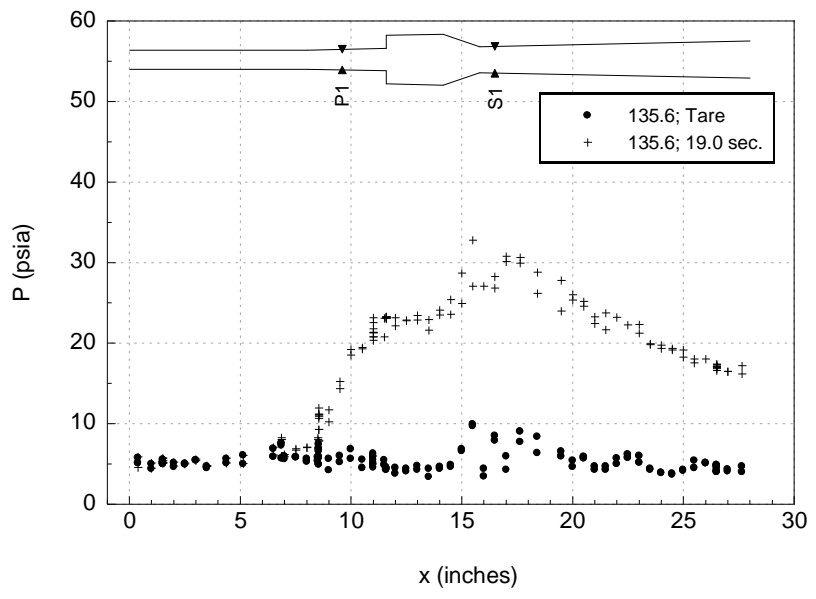

(c) Run 135.6, $M_{\infty}=7.5$

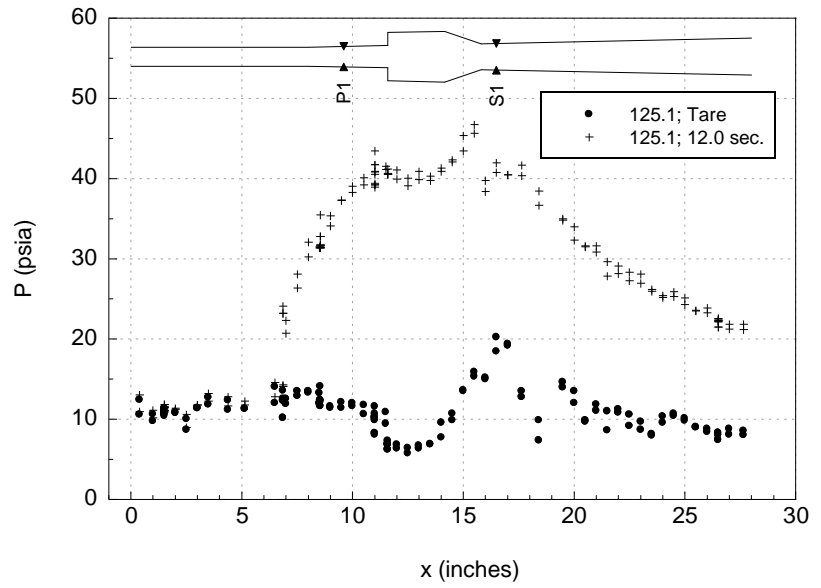

(b) Run 125.1, $M_{\infty}=6.5$

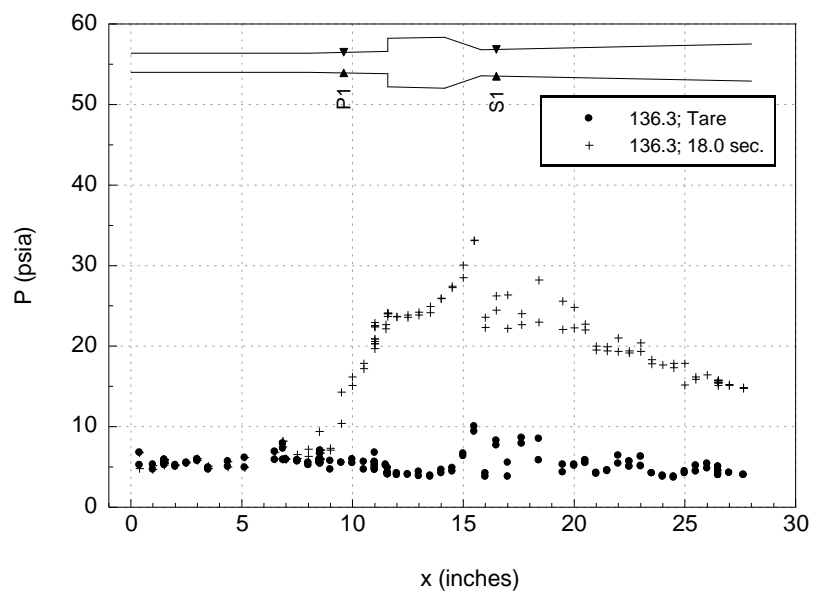

(d) Run 136.3, $M_{\infty}=8.0$

Figure 2. Pressure distributions from selected ground test cases.

The VULCAN CFD solutions were one-dimensionalized using a mass-flux weighted average according to

$$
\bar{\alpha}=\frac{\int \alpha \rho(\vec{U} \cdot \vec{n}) d A}{\int \rho(\vec{U} \cdot \vec{n}) d A}
$$

where $\alpha$ is the variable to be one-dimensionalized, $\rho$ is the density, $\vec{U}$ is the velocity vector, $\vec{n}$ is the unit vector normal to the cross-sectional plane, and $A$ is the area over which the average is being performed.

CFD++ is a general-purpose CFD tool developed by Metacomp Technologies. ${ }^{14} \mathrm{CFD}++$ uses a finite-volume numerical framework, with multi-dimensional TVD schemes and Riemann solvers for accurate representation of supersonic flows. Multi-grid acceleration is available to provide a fast and accurate solution methodology for both steady and unsteady flows. A variety of one-, two-, and three-equation turbulence models are available for RANS calculations, along with LES and hybrid RANS/LES options. Chemically reacting flows can be handled with a general finite-rate kinetics model or a user specified function for chemistry. The code supports both structured (quadrilateral and hexahedral) and unstructured (triangle, prism, and tetrahedral) grids. Message Passing Interface (MPI) is used to take advantage of modern parallel-processing computers. 
CFD++ has several types of Riemann solvers; the HLLC (Harten Lax van Leer Contact) Riemann solver with Minmod flux limiting was used in the current simulations. Unless otherwise specified, turbulence was modeled with the two-equation cubic $k-\varepsilon$ model. This model has non-linear terms that account for normal-stress anisotropy, swirl, and streamline curvature. At solid surfaces, an advanced two-layer wall function with the blended mode of equilibrium and non-equilibrium was employed to reduce grid requirements. The turbulent $\mathrm{Schmidt}\left(S c_{t}\right)$ and Prandtl $\left(P_{t}\right)$ numbers control the modeled turbulent transport of mass and energy, respectively, and they were set to constant values. The value for $S c_{t}$ and the compressibility correction were varied to best match the experimental data shown in Table 3 and Figure 2. The value for $\operatorname{Pr}_{t}$ was selected to be 0.9. Chemical reactions were modeled using the reduced kinetic mechanism generated by the Princeton University ${ }^{15}$. This mechanism consists of 22 species and it was developed based on the detailed mechanism of Wang and Laskin. ${ }^{16}$

Three-dimensional CFD data were reduced to equivalent one-dimensional results using the separated-flow averaging technique. This method uses two distortion terms and results in the preservation of mass, momentum, and energy flows along with the pressure force and kinetic energy flow while introducing little artificial entropy gain. In this method, the projected areas $\left(A_{i}\right)$, mass flow $(W)$, momentum flows $\left(\mathrm{mom}_{i}\right)$, total energy flow $(E)$, pressure force in each direction $\left(P A_{i}\right)$, and kinetic energy flow $(K E)$ are determined by integrating the CFD solution. Species mass fractions are determined from the ratio of each species flow to the total mass flow. The static pressure is found using

$$
P=\frac{P \vec{A} \cdot \vec{A}}{\vec{A} \cdot \vec{A}}
$$

The static enthalpy is determined from

$$
h=\frac{E-K E}{W} .
$$

The density, temperature, and entropy are then determined using the equation of state that was used in the CFD solver. Next, the velocity components are found using

$$
U_{i}=\frac{m^{\prime} m_{i}-P A_{i}}{W} \text { for } \mathrm{i}=\mathrm{x}, \mathrm{y}, \mathrm{z} .
$$

Finally, the extra distortion terms are found using

$$
\eta_{a}=\frac{W}{\rho(\vec{U} \cdot \vec{A})}, U_{c}=\frac{2 K E}{W(\vec{U} \cdot \vec{U})} \cdot
$$

Typically, the distortion terms remain near unity for non-separated flows. In these cases, the separated flow averaging technique yields values that are very close to other averaging procedures. For separated flows like those encountered in shock trains and over cavity flameholders, the value of $\eta_{a}$ decreases to mimic the effective flow area.

Burned equivalence ratio was computed at the combustor exit station using $\phi_{B}=\phi^{*} \eta_{c}$. In this expression, the combustion efficiency at the combustor exit is computed based on static enthalpy change using

$$
\eta_{c}=\frac{h\left(T_{r e f}, Y_{i}\right)-h\left(T_{r e f}, Y_{i, r e f}\right)}{h\left(T_{r e f}, Y_{i, \text { ideal }}\right)-h\left(T_{r e f}, Y_{i, r e f}\right)},
$$

where the reference condition is based on the mass flow rate at the isolator entrance, the total air flow rate, and the total fuel flow rate, and the ideal condition is determined from an equilibrium calculation using the static pressure and static enthalpy at the combustor exit station. Both VULCAN and CFD++ use this expression to compute combustion efficiency.

In order to judge whether a particular solution was converged, criteria were established for each code based on the established best practices. VULCAN solutions were considered converged when the mass flow error was less than $0.2 \%$ and the residual showed an order of magnitude decrease on the finest grid. For the CFD ++ calculations, the relative change of mass conservation was reduced to about $0.1 \%$ and the residuals for the governing equations were no longer increasing. 


\section{Ground Test Simulation Results}

At the conclusion of the first phase of HDCR ground tests, CFD simulations were run to match selected ground test data and calibrate the tool input parameters. Several studies were conducted to determine the best grid size, appropriate turbulent Schmidt number, and application of a compressibility correction. The quality of the simulation was assessed by the location of the pressure rise in the isolator region and the magnitude of the pressure peak in the combustor. All of the results shown here were obtained with CFD++, but parallel studies performed with VULCAN produced similar results.

\section{A. Grid Sensitivity}

Because the accuracy of the results can be strongly influenced by the size of the grid, two grids were run to determine whether a coarser grid would provide accurate, but computationally faster, results. Each grid represented one quarter of the rig geometry and included the facility nozzle. The coarse grid contained 1.4 million cells while the fine grid contained 11.1 million cells. As shown in Figure 3, the one-dimensional pressure results are very similar. Running on 96 processors, the fine grid required about two months to reach convergence whereas the coarse grid only required ten days. Because of the similarity of the results and the large reduction in run time, the coarse grid of 1.4 million cells was chosen to run the CFD++ simulations in the rest of this paper. A similar study was performed using VULCAN, resulting in a grid size of 6.4 million cells with a maximum combustor $y^{+}$of 30 . The VULCAN cases were run on 120 processors and required about 3 days of runtime.

\section{B. Turbulence Treatment}

The turbulent Schmidt number is the ratio of the eddy viscosity to the eddy mass diffusivity. It controls the turbulent mixing rate of the fluids in a CFD simulation. Lower values of the turbulent Schmidt number enhance the turbulent mixing of the solution. Because the experimental data showed dual-mode operation at the low Mach numbers (5.84 and 6.5) and scramjet-mode operation at the high Mach numbers (7.5 and 8.0), at least two different turbulent Schmidt number values were anticipated. Each set of data (see Table 3) was run with varying Schmidt numbers to determine the best value for that set of data. Results are shown in Figure 4. The best match for runs 123.1 and 125.1, which exhibit dual-mode operation, was $\mathrm{Sct}=0.6$. For scramjet-mode operation, as in runs 135.6 and 136.3, the Sct was set to 0.3 to best match the data. Also, note that the compressibility correction (CC) was activated for the higher Mach number cases (runs 135.6 and 136.3). This parameter corrects the over-mixing of high speed shear layers predicted by two-equation turbulence models. In the HDCR geometry, the cavity region is a shear layer region of particular concern. Again, all of the baseline experimental data cases were run with the calibrated turbulent Schmidt number and with the compressibility correction factor on and off. The results are shown in Figure 5. For runs 123.1 and 125.1, the best match is obtained with the compressibility correction turned off. The results calculated with the compressibility correction turned on show an overshoot in the pressure rise in the isolator as well as the cavity close-out. Also, the pressure does not match the data as well near the combustor exit. The higher Mach number data, runs 135.6 and 136.3, require the compressibility correction factor be turned on. Although the results with the compressibility correction turned off produce a better match at the combustor exit, the pressure data is matched much better in the isolator and cavity areas with the compressibility correction turned on.

Using the results of these input parameter studies, a standard practice was adopted for all of the HDCR data analyses and HIFiRE 2 flight predictions. Table 4 shows parameter selections for dual-mode and scramjet-mode simulations using both CFD ++ and VULCAN.

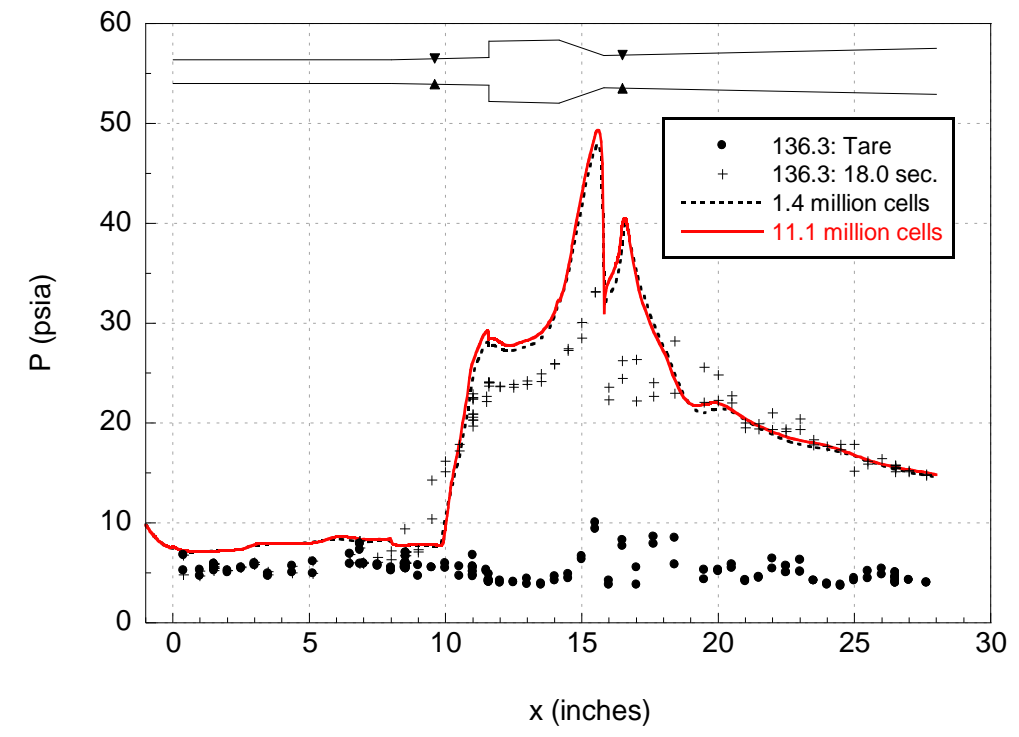

Figure 3. Grid sensitivity results of one-dimensional pressure, run 136.3, $M_{\infty}=8.0$. 


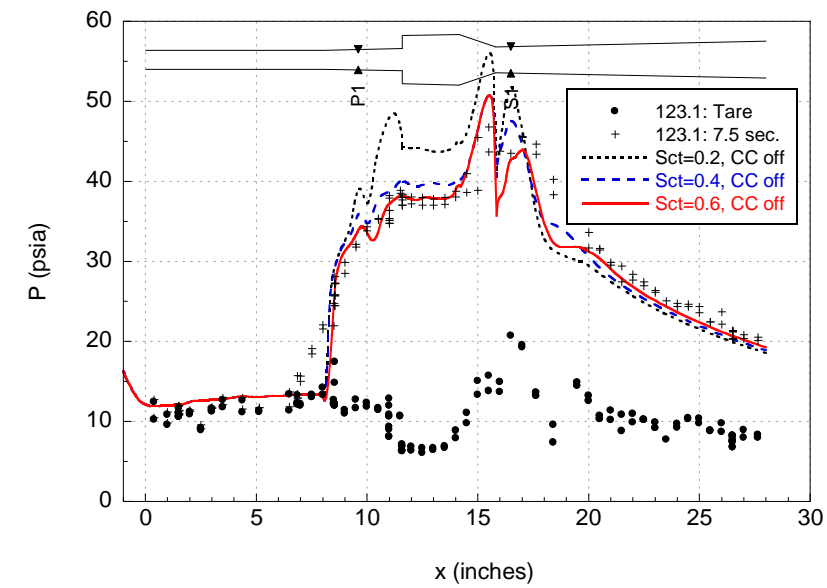

(a) Run 123.1, $M_{\infty}=5.84$

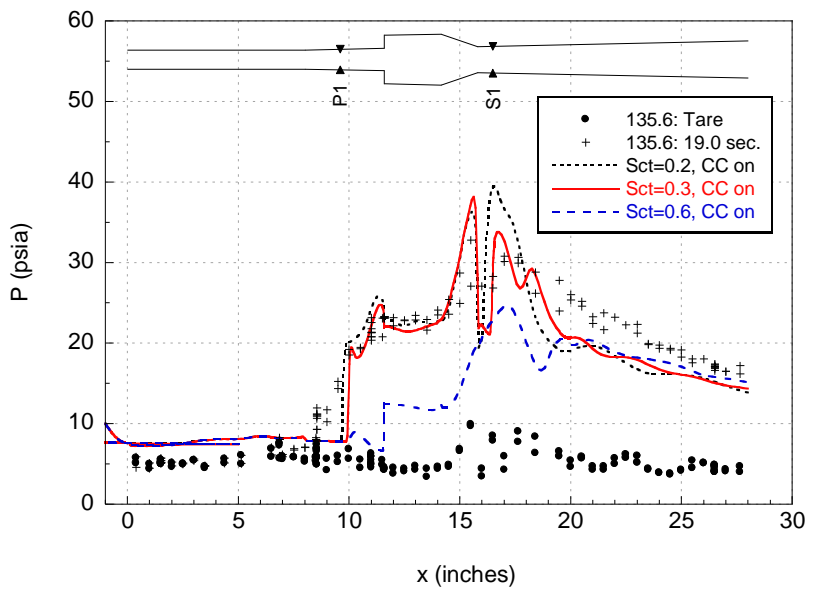

(c) Run 135.6, $M_{\infty}=7.5$

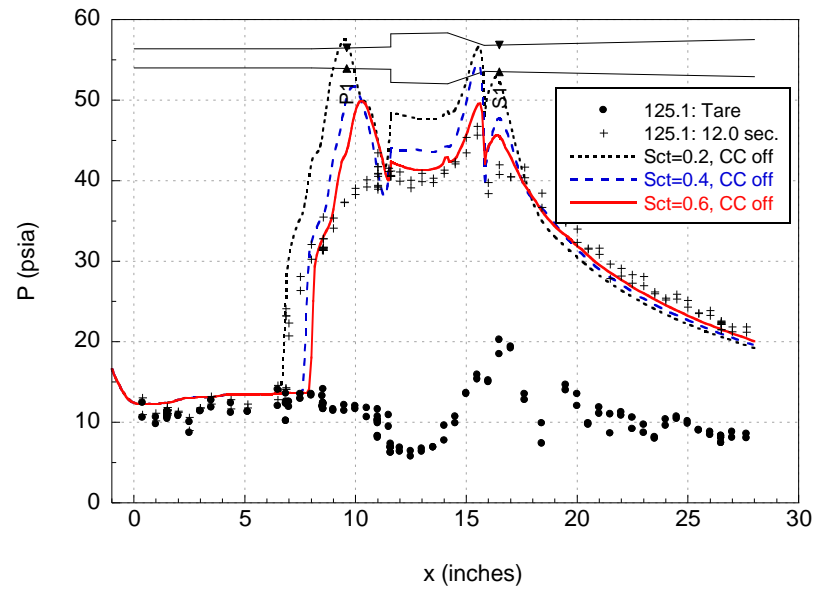

(b) Run 125.1, $M_{\infty}=6.5$

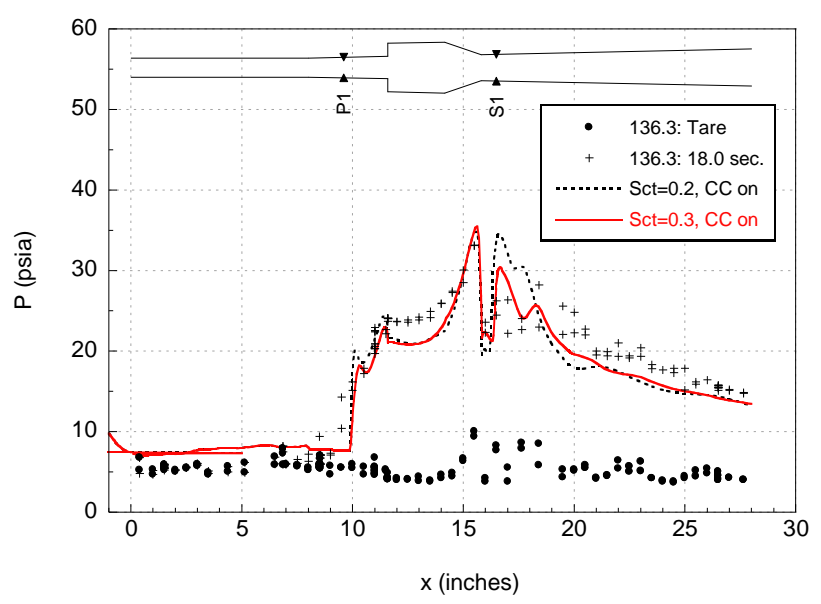

(d) Run 136.3, $M_{\infty}=8.0$

Figure 4. Sensitivity of one-dimensional pressure to turbulent Schmidt number.

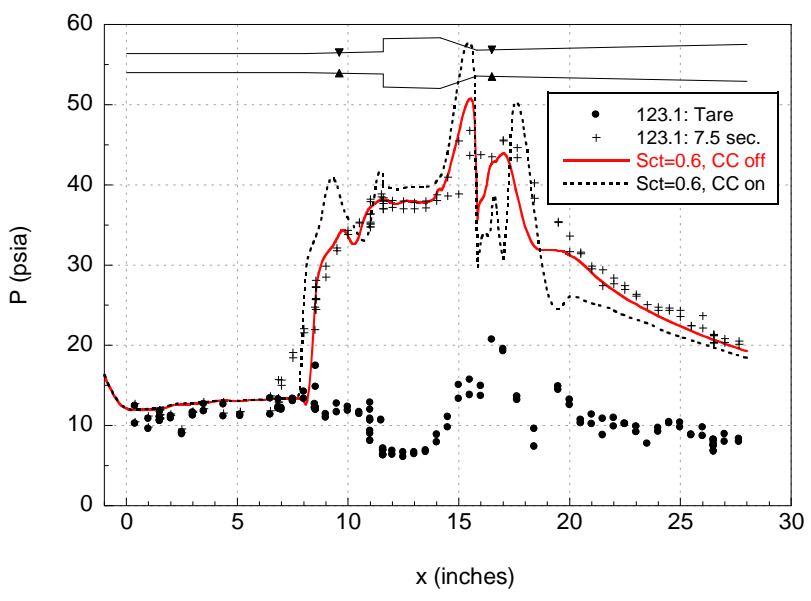

(a) Run 123.1, $M_{\infty}=5.84$

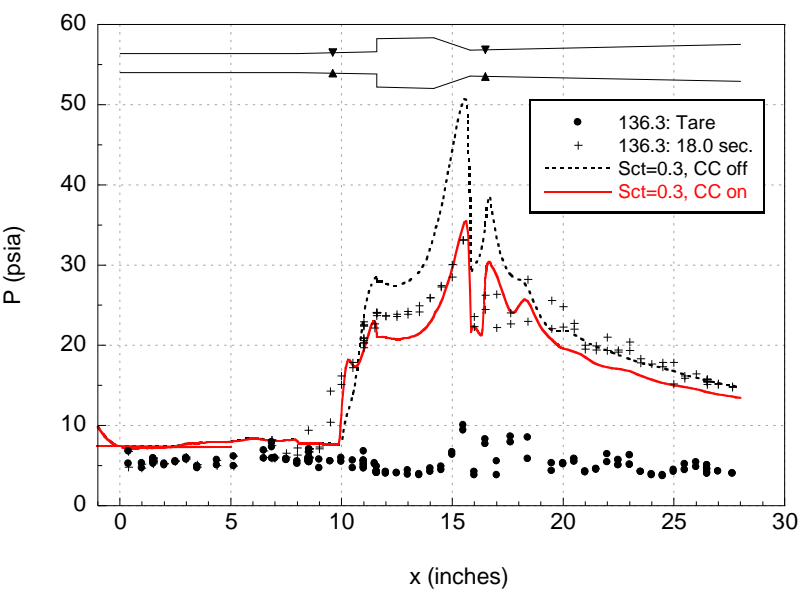

(b) Run 136.3, $M_{\infty}=8.0$

Figure 5. One-dimensional pressure showing sensitivity to compressibility correction. 
Table 4. Standard practice for HDCR and HF2 flight predictions.

\begin{tabular}{c|c|c|c|c}
\hline \hline \multirow{2}{*}{ Operating Mode } & \multicolumn{2}{|c|}{ CFD++ } & \multicolumn{2}{c}{ Vulcan } \\
\cline { 2 - 5 } & $\mathbf{S c}_{\mathbf{t}}$ & $\mathbf{C C}$ & $\mathbf{S c}_{\mathbf{t}}$ & $\mathbf{C C}$ \\
\hline Dual-Mode & 0.6 & Off & 0.5 & Off \\
\hline Scramjet-Mode & 0.3 & On & 0.325 & On \\
\hline \hline
\end{tabular}

\section{Results from Calibrated Tools}

Combustor pressure distributions obtained from the calibrated CFD tools are shown in Figure 6 along with the companion data from the experiment. In these plots, the one-dimensional data from the CFD simulations are shown along with all of the measured pressure data from the experiment. During ground testing, an arbitrary constraint on isolator margin was applied during dual-mode operation in an attempt to account for anticipated uncertainties in the flight experiment (e.g., angle of attack, dynamic pressure, and fuel flow rate) and their influence on isolator operability. The station at $\mathrm{x}=4$ inches was selected (50\% isolator length), and fuel distributions that positioned the pre-combustion shock train upstream of this location were deemed unsatisfactory for the flight fuel schedule. Several other features are worth noting in the figure. First, the general agreement between the two CFD codes is quite good, especially in the dual-mode operation cases, despite the fact that the grids, turbulence models, and combustion kinetics models are different between the codes. Second, using the calibrated input parameters, the comparisons with experimental data are also quite good. For dual-mode operation, the axial position of the pre-

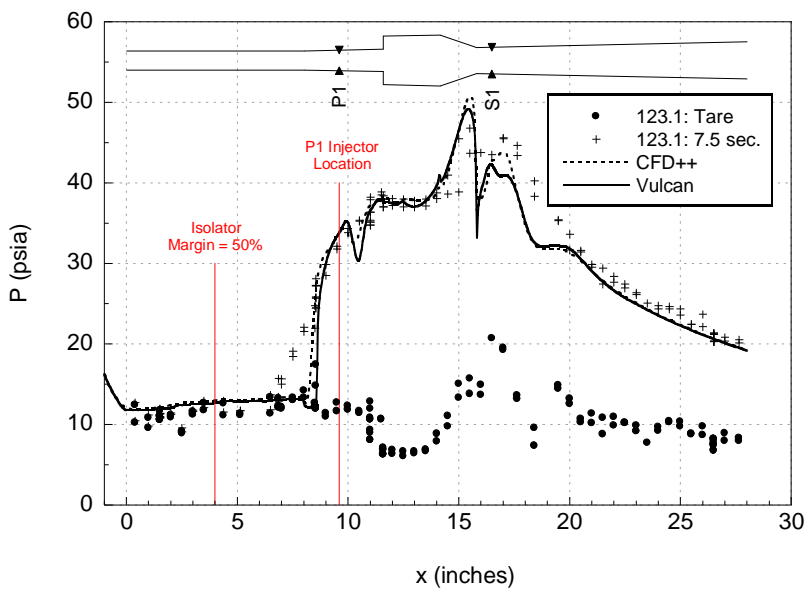

(a) Run 123.1, $M_{\infty}=5.84$

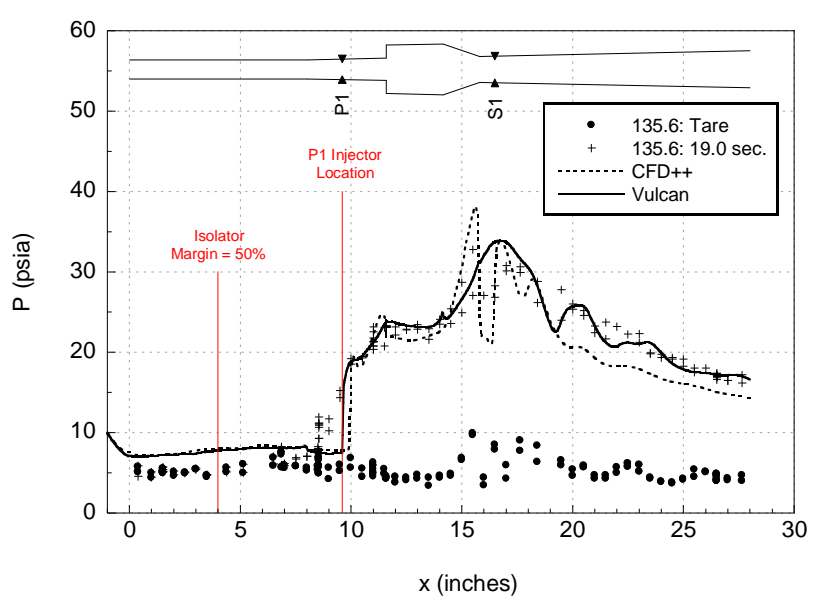

(c) Run 135.6, $M_{\infty}=7.5$

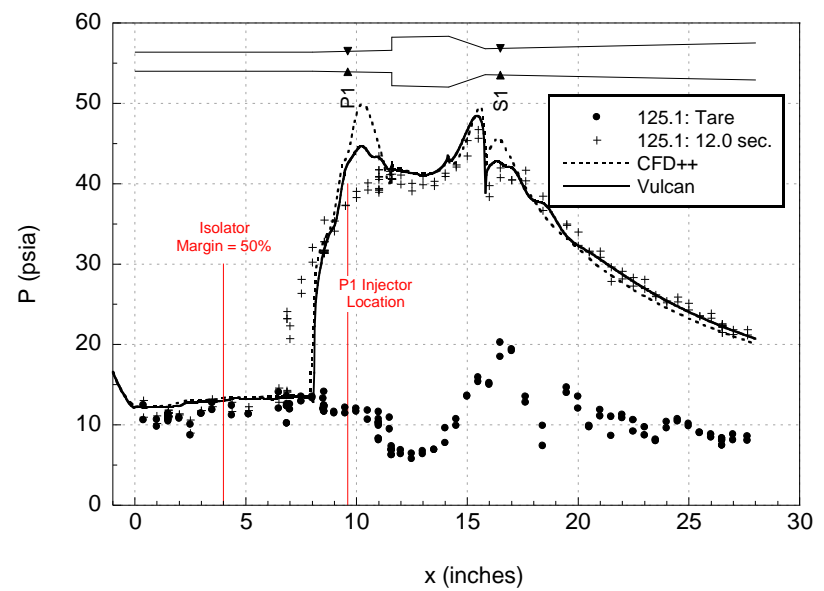

(b) Run 125.1, $M_{\infty}=6.5$

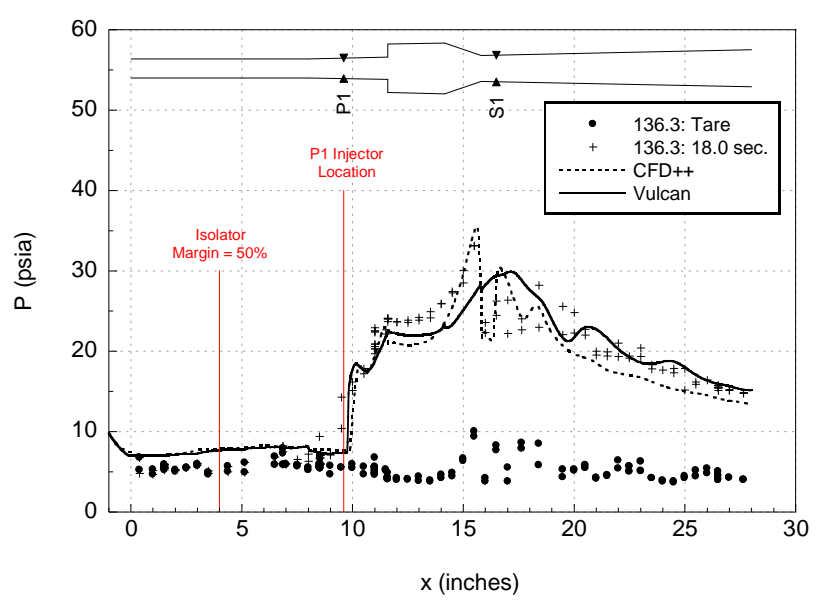

(d) Run 136.3, $M_{\infty}=8.0$

Figure 6. One-dimensional pressure distributions from experiment and CFD simulations. 
combustion shock train is well-captured along with the peak pressure in the vicinity of the cavity flameholders. The start of the pressure rise and the peak pressure are also well-predicted in the high Mach cases. However, in the Mach 7.5 and 8 simulations, CFD++ consistently underpredicts the level of pressure rise downstream of the cavity flameholders while VULCAN does a better job matching the experimental data in this region. Third, at higher Mach number conditions, the CFD codes generally overpredict the isolator entrance pressure (i.e., the pressure at $\mathrm{x}=0$ inches). For these test conditions, it is expected that two elements combine to cause this phenomenon. The first is that the physical throat area of the facility nozzle is expected to experience some distress at the high stagnation temperatures and pressures required for simulating these flight conditions. Post-test nozzle throat height measurements have shown a nozzle height reduction of as much as 5.7\% at Mach 6 and 5.4\% at Mach 8. The second potential contributor is that, at the high stagnation temperatures encountered in these test conditions, there is a high probability of thermodynamic non-equilibrium in the air flow entering the isolator. Neither CFD code is currently equipped to model this phenomenon. Both of these observations would drive the CFD simulations to predict a higher static pressure entering the isolator. Details of these discrepancies can be found in Reference 8 .

One-dimensional Mach number distributions through the isolator/combustor flowpath are shown in Figure 7 for the Mach 7.5 and 8 cases. The Mach number begins to drop sharply just downstream of the primary fuel injector location for both cases. As expected, the minimum Mach number occurs just downstream of the cavity ramp region followed by gradual acceleration to the combustor exit. As shown in Table 1, the flight engine must operate in scramjetmode at Mach 8. For the HF2 project, scramjet-mode is satisfied by meeting two criteria: no significant pressure rise ahead of the primary injector and a onedimensional Mach number (as verified through analyses) greater than unity throughout the flowpath. The results in Figure 6 and Figure 7 satisfy this definition of scramjet-mode for these inflow and fueling conditions, as the minimum Mach number in the flowpath is always supersonic and the pressure rise begins in the vicinity of the primary fuel injectors.

Finally, Table 5 contains combustion performance results from the cases studied. These results indicate good combustion efficiencies for all four cases. Recall that the two solvers used different mechanisms to solve for the chemistry in the reacting flow. Also, for the scramjetmode conditions, the $\mathrm{CFD}++$ results underpredicted the combustor pressure downstream of the cavity flameholders. This leads to a commensurate underprediction of the wall pressure force (and, therefore, combustor exit stream thrust and combustion efficiency). As such, it is not surprising that the combustion efficiency results from the two codes are somewhat different, especially

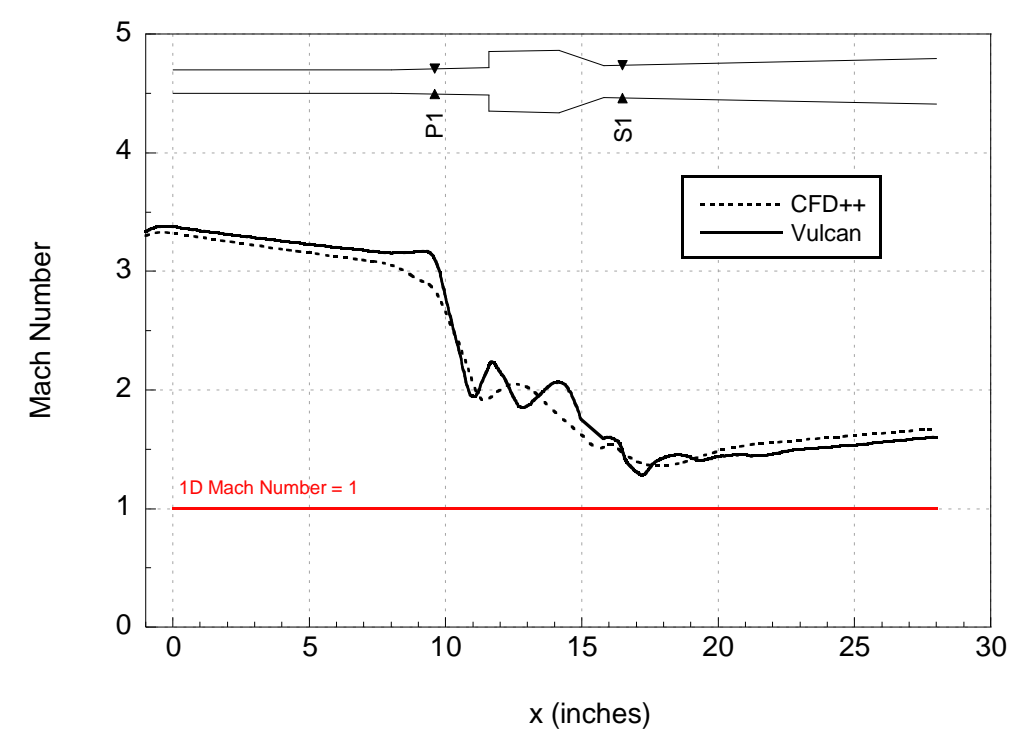

(a) Run 135.6, $M_{\infty}=7.5$

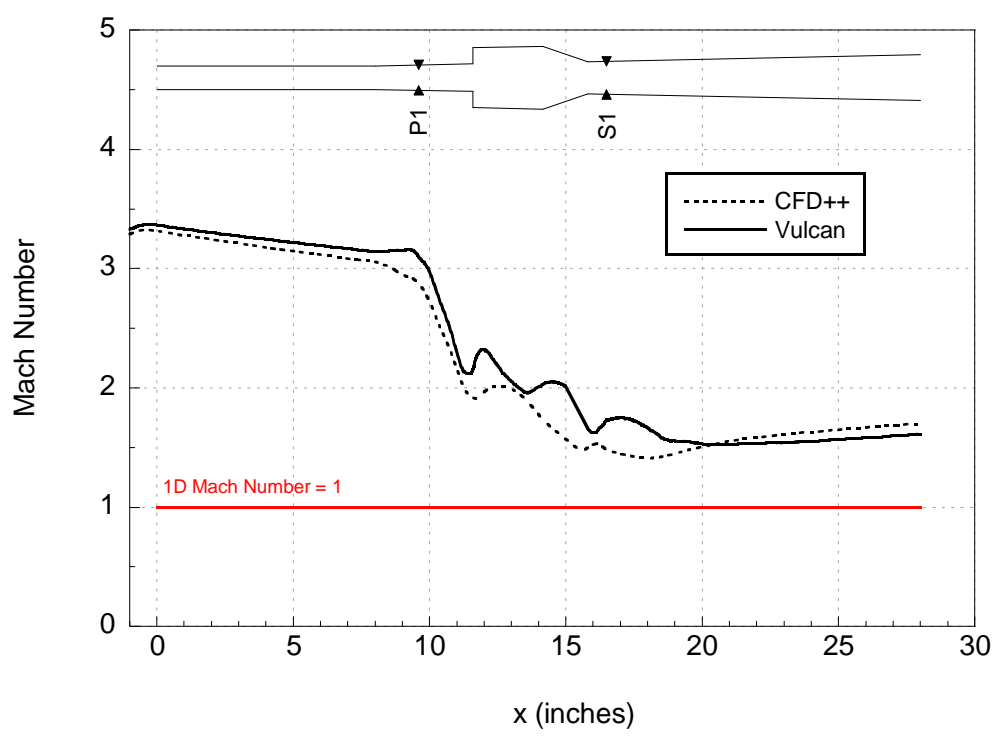

(b) Run 136.3, $M_{\infty}=8.0$

Figure 7. One-dimensional Mach number distributions from CFD simulations. 
for Mach 7.5 and 8.0 conditions. As noted in Table 1, the only combustion performance objective for this flight experiment is associated with the Mach 8 flight condition $\left(\phi_{B} \geq 0.7\right)$. The results shown in Table 5 for this condition suggest this objective can be met with substantial margin.

Table 5. HDCR combustion performance results from CFD simulations.

\begin{tabular}{c|c|c|c|c|c}
\hline \hline \multirow{2}{*}{$\begin{array}{c}\text { Test Reference } \\
\text { (Run \#; time slice) }\end{array}$} & Simulated Flight & \multicolumn{2}{|c|}{ CFD++ } & \multicolumn{2}{c}{ VULCAN } \\
\cline { 3 - 6 } & Mach Number & $\eta_{\mathbf{c}}$ & $\phi_{\mathbf{B}}$ & $\eta_{\mathbf{c}}$ & $\phi_{\mathbf{B}}$ \\
\hline $123.1 ; 7.5 \mathrm{sec}$. & 5.84 & $86.8 \%$ & 0.56 & $91.0 \%$ & 0.59 \\
\hline $125.1 ; 12.0 \mathrm{sec}$. & 6.5 & $85.9 \%$ & 0.86 & $84.0 \%$ & 0.84 \\
\hline $135.6 ; 19.0 \mathrm{sec}$. & 7.5 & $81.2 \%$ & 0.81 & $93.0 \%$ & 0.93 \\
\hline $136.3 ; 18.0 \mathrm{sec}$. & 8.0 & $83.6 \%$ & 0.84 & $93.0 \%$ & 0.93 \\
\hline \hline
\end{tabular}

\section{Flight Test Prediction Results}

In order to predict the performance of the engine during flight, the flight geometry was run using the CFD model calibrated by matching HDCR data. The flight geometry is identical to the ground test geometry from the isolator entrance plane to the combustor exit plane. As illustrated in Figure 8, the flight geometry includes a forebody and inlet. The forebody surfaces commence with a nine-inch opening followed by opposing planar surfaces 32.8 inches long, at a constant $7^{\circ}$ compression angle, leading to the inlet. The inlet is 4.8 inches wide and 1.0 inch high at the mouth and 7.63 inches long with a $3^{\circ}$ lateral compression on each sidewall. Details on the forebody and inlet design can be found in Reference 17.

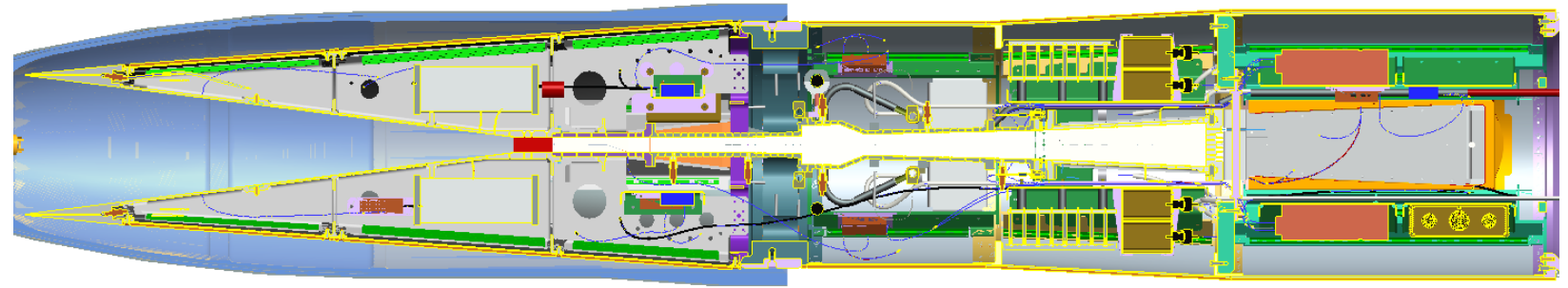

Figure 8. Side view of HIFiRE Flight 2 geometry.

Although a baseline fuel schedule was identified through ground testing, a slightly modified schedule will be tested in flight. The modified schedule delays the start of fueled operation slightly to take advantage of expanded operability margin at Mach 6.5. This change allows the flight fuel system to be simplified while still achieving all of the science objectives. Figure 9 shows the flight fuel schedule. By following this schedule, the flight test maintains a constant fuel split of $\phi_{P I / S I}=0.4 / 0.6$ during the test window. The total fuel-air equivalence ratio remains equal to 1.0 from Mach 6.5 to 8 while transitioning from dual-mode to scramjet-mode operation.

CFD++ model predictions for onedimensional pressure versus axial location for nominal flight conditions are shown in Figure 10a. As expected, the analyses show that the pressure rise occurs ahead of the primary injector for Mach 6.0 and 6.5 flight conditions, exhibiting dual-mode operation. Less than $50 \%$ of the isolator is utilized, allowing margin for uncertainties in the flight trajectory, angle of attack, and fueling levels. Between Mach 7.0 and 8.0,

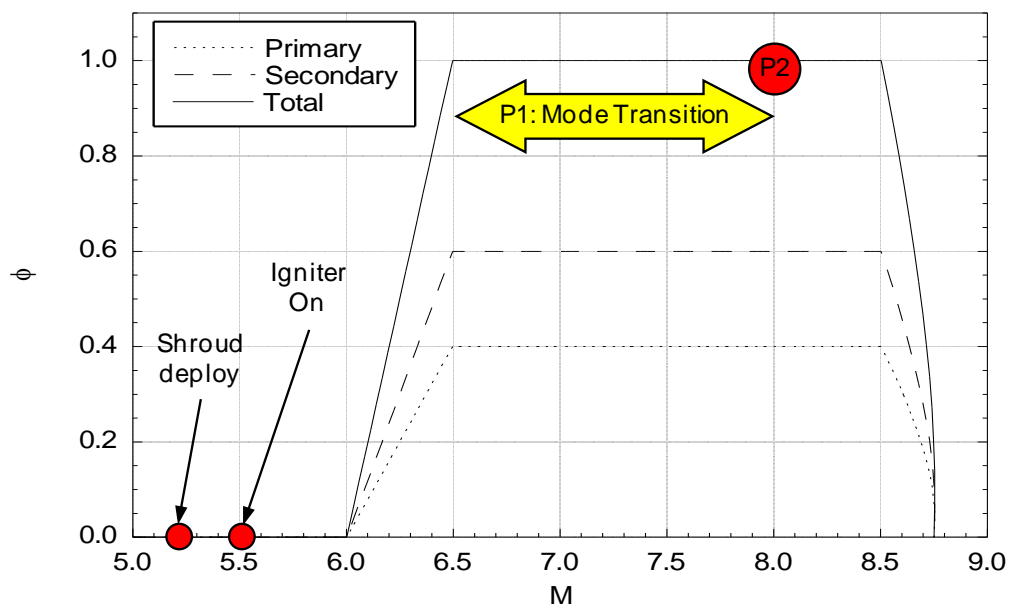

Figure 9. Baseline flight fuel schedule. 


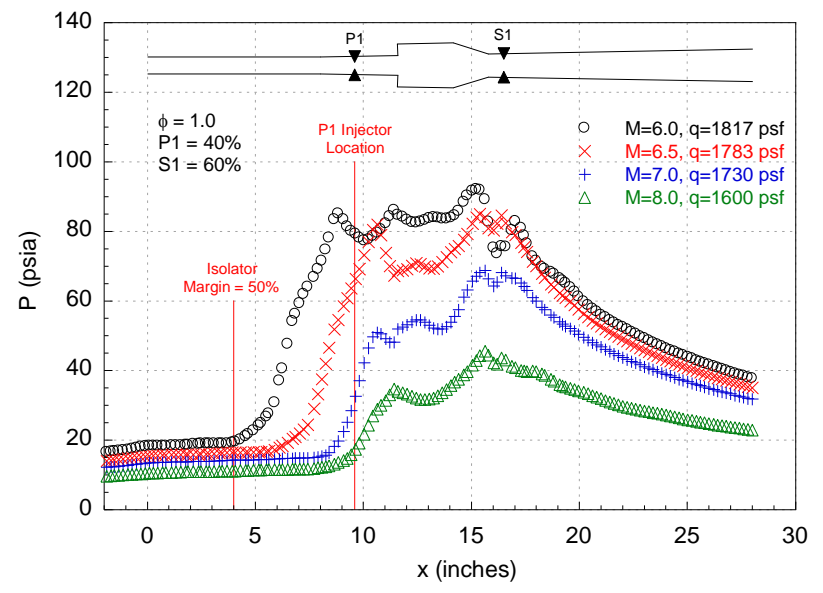

(a) Static pressure

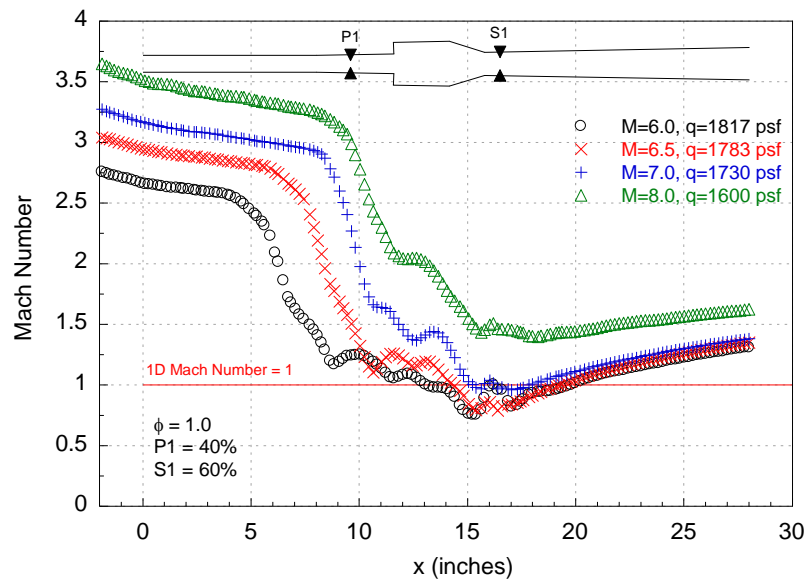

(b) Mach number

Figure 10. Flight CFD one-dimensional static pressure and Mach number predictions.

the pressure rise is downstream of the primary injector, indicating scramjet-mode operation, as required by the flight science objectives (see Table 1).

The one-dimensional Mach number in the flight flowpath, as predicted by CFD++, is shown in Figure 10b for Mach 6.0, 6.5, 7.0, and 8.0 flight cases. As in the ground test data analyses, the Mach number drops sharply in the vicinity of the primary injector for Mach 7.0 and 8.0. Although the Mach 7.0 case does not meet the criteria for pure scramjet-mode (1-D Mach drops below 1.0), the Mach 8.0 prediction does meet the scramjet-mode definition and satisfies the flight science objectives.

Table 6 provides the burned fuel equivalence ratios, as calculated by the calibrated CFD++ model for four nominal flight cases. The flight requirement for $\phi_{B}>0.70$ at Mach 8.0 is achievable and is predicted to be met with substantial margin. These results indicate that HF2 can be successful in meeting all objectives with the nominal flight trajectory.

Table 6. Flight combustion performance results predicted by CFD++ simulations.

\begin{tabular}{c|c|c|c|c|c}
\hline \hline $\mathbf{M}_{\infty}$ & $\mathbf{q}_{\infty}$ (psf) & $\phi_{\text {TOTAL }}$ & $\phi_{\text {P1 }}$ & $\phi_{\mathbf{S 1}}$ & $\phi_{\mathbf{B}}$ \\
\hline 6.0 & 1817 & 1.0 & 0.4 & 0.6 & 0.84 \\
\hline 6.5 & 1783 & 1.0 & 0.4 & 0.6 & 0.91 \\
\hline 7.0 & 1730 & 1.0 & 0.4 & 0.6 & 0.92 \\
\hline 8.0 & 1600 & 1.0 & 0.4 & 0.6 & 0.90 \\
\hline \hline
\end{tabular}

\section{Conclusions}

In support of HIFiRE Flight 2, experimental ground test data were chosen to calibrate the analysis tools used for flowpath analyses. This was accomplished for four ground test cases at different simulated flight enthalpies. The results were used to predict flight flowpath performance and ensure that margin exists in the flight hardware to successfully achieve all flight science objectives.

Several sensitivity studies were run using CFD++ and VULCAN computational codes to determine the best grid size, turbulent Schmidt number, and compressibility correction. A coarse grid was used in the analyses because it provided accurate results, but required less computational time to run. The turbulent Schmidt number was varied for all four test cases, but ultimately resulted in two calibrated values: one for dual-mode operation and another for scramjet-mode operation. At low Mach, dual-mode simulations, the compressibility correction is not required to match experimental data, but at high Mach, scramjet-mode simulations, it proved beneficial. These studies provided a standard practice to be used in all HIFiRE Flight 2 analyses, including ground test data calibration and flight performance predictions. Comparisons between the results calculated by CFD++ and VULCAN were favorable, providing confidence in the simulations.

Using the calibrated CFD model, flight simulations were run for four trajectory points. The results show that all combustion performance flight science objectives can be met. Dual-mode operation was demonstrated at Mach 6.0 
through 7.0. At Mach 8.0, the model predicts no significant pressure rise ahead of the primary injector and a onedimensional Mach number greater than unity throughout the flowpath. These two criteria define the required scramjet-mode operation in flight. In addition, the model predicts a burned fuel equivalence ratio of 0.90 at Mach 8.0 , providing confidence that the burned fuel equivalence ratio in flight will be at least 0.70 , as required.

Once the HIFiRE Flight 2 experiment is successfully completed and the data has been analyzed, the calibration of CFD tools described here will be verified. This information will be valuable in future flight projects as a means to bridge the differences between direct-connect ground tests and atmospheric flight tests of dual-mode scramjet engines.

\section{References}

\footnotetext{
${ }^{1}$ Jackson, K. R., Gruber, M. R., and Barhorst, T. F., "The HIFiRE Flight 2 Experiment: An Overview and Status Update," AIAA Paper 2009-5029, August 2009.

${ }^{2}$ Smart, M. K., Hass, N. E., and Paull, A., "Flight Data Analysis of the HyShot 2 Scramjet Flight Experiment," AIAA Journal, Vol. 44, No. 10, 2006, pp. 2366-2375.

${ }^{3}$ Walker, S. H., Rodgers, F. C., and Esposita, A. L., "Hypersonic Collaborative Australia/United States Experiment (HYCAUSE)," AIAA Paper 2005-3254, May 2005.

${ }^{4}$ Gruber, M., Jackson, K., Jackson, T., and Liu, J., "Hydrocarbon-Fueled Scramjet Combustor Flowpath Development for Mach 6-8 HIFiRE Flight Experiments," JANNAF 55th Propulsion Meeting, Newton, MA, May 2008.

${ }^{5}$ Guy, R. W., Rogers, R. C., Puster, R. L., Rock, K. E., and Diskin, G. S., "The NASA Langley Scramjet Test Complex," AIAA Paper 96-3243, July 1996.

${ }^{6}$ Pellett, G. L., Dawson, L. C., Vaden, S.. N., and Wilson, L. G., "Nitric Oxide and Oxygen-Air Contamination Effects on Extinction Limits of Non-premixed Hydrocarbon-Air Flames for a HIFiRE Scramjet", JANNAF $43^{\text {rd }}$ CS / $31^{\text {st }}$ APS / $25^{\text {th }}$ PSHS Joint Subcommittee Meeting, December, 2009, La Jolla, CA.

${ }^{7}$ Hass, N., Cabell, K., and Storch, A., "HIFiRE Direct-Connect Rig (HDCR) Phase I Ground Test Results from the NASA Langley Arc-Heated Scramjet Test Facility," JANNAF 43rd CS / 31st APS / 25th PSHS Joint Subcommittee Meeting, San Diego, CA, December 2009.

${ }^{8}$ Cabell, K., Hass, N., Storch, A. M., and Gruber, M., "Scramjet Test Results of the HIFiRE Direct-Connect Rig (HDCR) at NASA Langley's Arc-Heated Scramjet Test Facility," presented at $17^{\text {th }}$ AIAA International Space Planes and Hypersonic Systems and Technologies Conference, San Francisco, CA, April 11-14, 2011.

${ }^{9}$ VULCAN. http://vulcan-cfd.larc.nasa.gov. NASA Langley Research Center, Hampton, VA

${ }^{10}$ Wilcox, D. C., "Wall Matching, a Rational Alternative to Wall Functions," AIAA Paper 89-0611, Jan. 1989.

${ }^{11}$ Menter, F. R., "Two-Equation Eddy-Viscosity Turbulence Models for Engineering Applications," AIAA Journal, Vol. 32, No. 8, 1994, pp. 1598-1605.

${ }^{12}$ Edwards, J. R., "A Low Diffusion Flux-Splitting Scheme for Navier-Stokes Calculations," Computers and Fluids, Vol. 26, No. 6, 1997, pp. 635-659.

${ }^{13}$ Magnussen, B. F. and Hjertager, B. H., "On Mathematical Modeling of Turbulent Combustion with Special Emphasis on Soot Formation and Combustion," 16th Symposium (International) on Combustion, 1976.

${ }^{14}$ Metacomp, http://www.metacomptech.com/index.html, 2005.

15 Liu, J., Tam, C. J., Lu, T., and Law, C. K., "Simulations of Cavity-Stabilized Flames in Supersonic Flows Using Reduced Chemical Kinetic Mechanism," AIAA-2006-4862.

${ }^{16}$ Wang, H., and Laskin, A., "A Comprehensive Kinetic Model of Ethylene and Acetylene Oxidation at High Temperature," Internal Report for an AFOSR New World Vista Program, 1998.

${ }^{17}$ Ferlemann, P., "Forebody and Inlet Design for the HIFiRE 2 Flight Test," $55^{\text {th }}$ JANNAF Propulsion Meeting, Newton, MA, May 12-16, 2008.
} 